\title{
A round-trip ticket: the importance of release processes for in-stream nutrient spiraling
}

\author{
Daniel von Schiller ${ }^{1,4,8}$, Susana Bernal ${ }^{2,5,8}$, Francesc Sabater ${ }^{3,6}$, and Eugènia Martí ${ }^{2,7}$ \\ ${ }^{1}$ Catalan Institute of Water Research (ICRA), Scientific and Technological Park of the University of Girona, Emili Grahit 101, \\ Girona, Spain \\ ${ }^{2}$ Integrative Freshwater Ecology Group, Centre for Advanced Studies of Blanes (CEAB-CSIC), C/Accés a la Cala St. Francesc 17, \\ 17300, Blanes, Girona, Spain \\ ${ }^{3}$ Department of Ecology, University of Barcelona (UB), Diagonal 645, 08028, Barcelona, Spain
}

\begin{abstract}
Most nutrient-spiraling studies have focused on estimates of gross uptake $\left(U_{\text {gross }}\right)$, which show that streams take up dissolved inorganic nutrients very efficiently. However, studies based on estimates of net uptake $\left(U_{\text {net }}\right) \mathrm{em}$ phasize that streams tend to be at biogeochemical steady state (i.e., $U_{n e t} \approx 0$ ), at least on a time scale of hours. These findings suggest that streams can be highly reactive ecosystems but remain at short-term biogeochemical steady state if $U_{\text {gross }}$ is counterbalanced by release $(R)$, a process that remains widely unexplored. Here, we propose a novel approach to infer $R$ by comparing $U_{\text {net }}$ and $U_{\text {gross }}$ estimated from ambient and plateau concentrations obtained from standard short-term nutrient additions along a reach. We used this approach to examine the temporal variation of $R$ and its balance with $U_{\text {gross }}$ in 2 streams with contrasting hydrological regime (i.e., perennial vs intermittent) during 2 years. We focused on the spiraling metrics of $\mathrm{NH}_{4}{ }^{+}$and soluble reactive $\mathrm{P}(\mathrm{SRP})$, essential sources of $\mathrm{N}$ and $\mathrm{P}$ in stream ecosystems. $R$ differed substantially between the 2 streams. The perennial stream had a higher proportion of dates with $R>0$ and a $2 \times$ higher mean $R$ than the intermittent stream for both nutrients. Despite these differences, the magnitude of $R$ and $U_{\text {gross }}$ tended to be similar for both nutrients within each stream, which lead to $U_{\text {net }} \approx 0$ in most cases. A notable exception occurred for SRP in the intermittent stream, where $R$ tended to be higher than $U_{\text {gross }}$ during most of the winter period, probably because of desorption of $\mathrm{P}$ from stream sediments. Together, our findings shed light on the contribution of release processes to the dynamics of nutrient spiraling and support the idea that streams can be active ecosystems with high spiraling fluxes while simultaneously approaching short-term biogeochemical steady-state.
\end{abstract}

Key words: streams, nutrient spiraling, release, uptake, nitrogen, phosphorus

The nutrient spiraling concept describes the combined processes of nutrient cycling and downstream transport in running waters (Webster and Patten 1979, Newbold et al. 1981). According to this concept, the spiraling length is the average downstream distance travelled by a nutrient molecule until uptake (i.e., uptake length) plus the downstream distance travelled within an uptake compartment until release (i.e., turnover length). Uptake length depends on the importance of the gross uptake flux of dissolved nutrients from the water column by the active stream bed $\left(U_{\text {gross }}\right)$ relative to the downstream nutrient flux, whereas turnover length depends on the importance of the release flux by which those immobilized nutrients return to the water column $(R)$ relative to the downstream nutrient flux (Fig. 1A). Therefore, the balance between $U_{\text {gross }}$ and $R$ ultimately determines the net uptake flux $\left(U_{\text {net }}\right)$ of the ecosystem, and thus, whether it acts as a net nutrient source $\left(U_{\text {gross }}<R\right)$ or $\operatorname{sink}\left(U_{\text {gross }}>R\right)$, or whether it is at biogeochemical steady state $\left(U_{\text {gross }}=R\right)$, at least on a time scale of hours (Fig. 1B-D).

Most in-stream nutrient spiraling studies have focused on estimates of $U_{\text {gross }}$ and have shown that streams are highly reactive systems with a large capacity to take up dissolved inorganic nutrients (Peterson et al. 2001, Mulholland et al. 2008). In contrast, studies based on estimates of in-stream $U_{n e t}$ highlight that short-term biogeochemical steady state for dissolved inorganic nutrients is a common condition in streams (Brookshire et al. 2009, Bernal et al. 2012). However, further studies show that streams can act as net sinks of dissolved inorganic nutrients as a result of net algal growth during periods of open canopy (Roberts and Mulholland 2007) and postflood succession (Grimm 1987, Martí et al. 1997) or when in-stream denitrification is high (Heffernan et al. 2010). These apparently contradictory results imply that streams can be highly reactive (high $U_{\text {gross }}$ ) but still be at short-

E-mail addresses: ${ }^{4}$ dvonschiller@icra.cat; ${ }^{5}$ sbernal@ceab.csic.es; ${ }^{6}$ fsabater@ub.edu; ${ }^{7}$ eugenia@ceab.csic.es; ${ }^{8}$ Both authors contributed equally to this work 

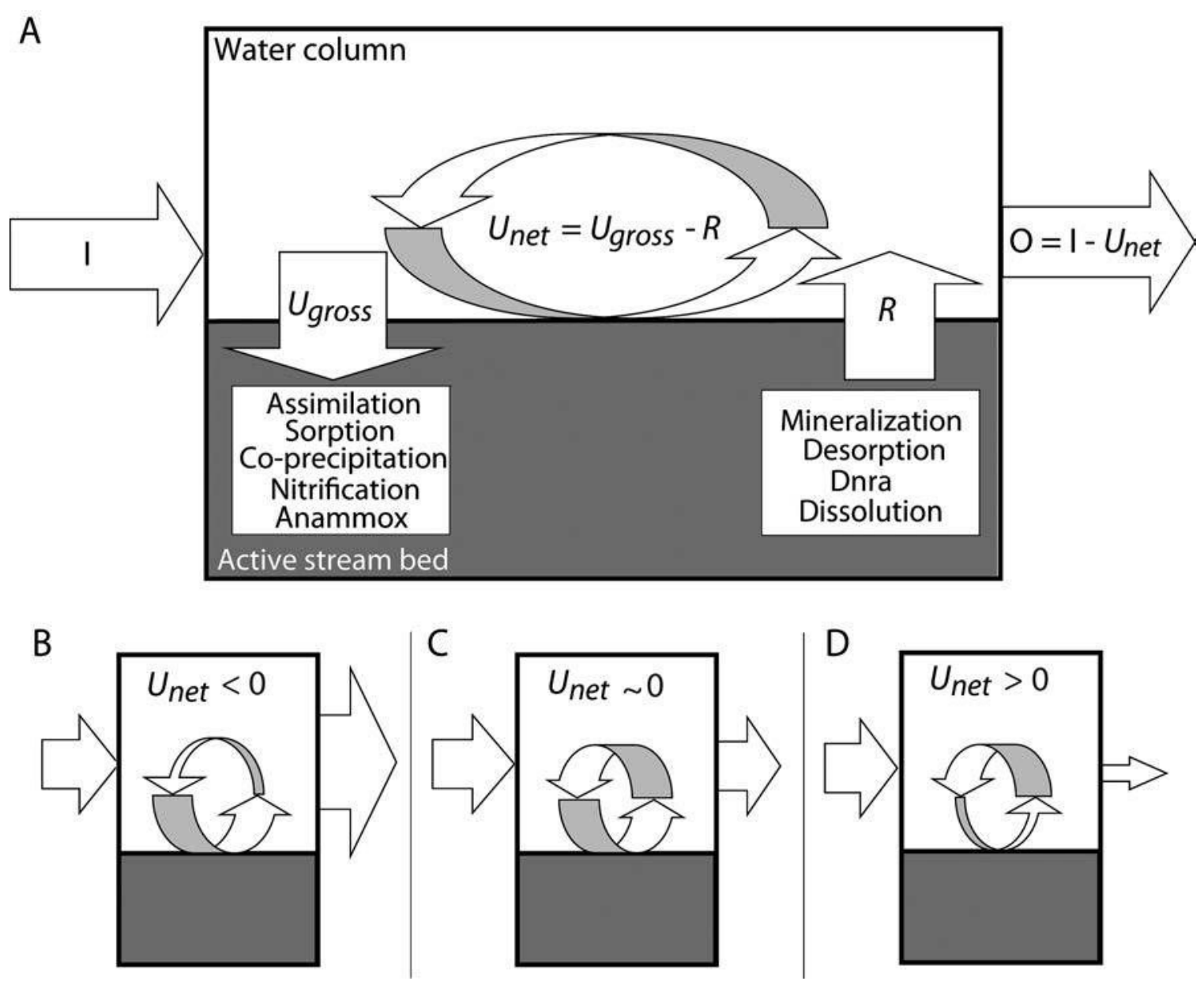

Figure 1. Conceptual diagram of $\mathrm{NH}_{4}{ }^{+}$and soluble reactive $\mathrm{P}$ (SRP) cycling in a headwater stream reach. A.-Dissolved inorganic nutrients enter the stream reach via upstream and lateral inputs $(I)$. Gross uptake flux $\left(U_{\text {gross }}\right)$ includes all biotic and abiotic processes occurring in the active stream bed of the reach that remove nutrients from the water column. $U_{\text {gross }}$ of $\mathrm{NH}_{4}{ }^{+}$includes assimilation by biota, nitrification, sorption onto stream sediments, and anaerobic $\mathrm{NH}_{4}{ }^{+}$oxidation (anammox). $U_{\text {gross }}$ of SRP includes assimilation, co-precipitation, and sorption. Release flux $(R)$ of $\mathrm{NH}_{4}{ }^{+}$and SRP from sediments back to the water column occurs via mineralization of organic matter (including ammonification), desorption, dissimilatory $\mathrm{NO}_{3}{ }^{-}$reduction to $\mathrm{NH}_{4}{ }^{+}$(dnra; only for $\mathrm{NH}_{4}{ }^{+}$), and dissolution (only for SRP). Net uptake flux $\left(U_{n e t}\right)$ is the balance between $U_{\text {gross }}$ and $R$ in the reach. The output of dissolved inorganic nutrients from the reach $(O)$ is the difference between $I$ and $U_{\text {net }}$. B-D.-Three possible scenarios for the stream acting as a net nutrient source $\left(U_{\text {net }}<0\right)$, short-term biogeochemical steady state $\left(U_{\text {net }} \sim 0\right)$, or net nutrient $\operatorname{sink}\left(U_{\text {net }}>0\right)$.

term biogeochemical steady state $\left(U_{\text {net }} \approx 0\right)$ if $U_{\text {gross }}$ is counterbalanced by $R$ (Fig. 1C). Thus, estimates of the flux of immobilized nutrients back to the water column $(R)$ are critical to gain a full picture of in-stream nutrient spiraling (Mulholland and Webster 2010). Furthermore, examining the balance between $R$ and $U_{\text {gross }}\left(U_{\text {net }}\right)$ provides key insights into the ultimate role of streams on regulating nutrient export to downstream ecosystems.

In-stream $U_{\text {gross }}$ can be empirically estimated from solute additions (Webster and Valett 2006), and in-stream $U_{\text {net }}$ can be derived from the longitudinal profiles of ambient dissolved inorganic nutrient concentrations (Brookshire et al. 2009, von Schiller et al. 2011b). However, direct fluxes of in-stream $R$ can be measured only by using solute additions of radioactive or stable-isotope tracers (Newbold et al. 1983, Peterson et al. 2001). These isotopic techniques can be difficult to apply, are expensive, and have low utility for studying the temporal dynamics of spiraling metrics because isotopic signals persist within the ecosystem for different lengths of time because of differences in turnover among ecosystem compartments (Newbold et al. 1983, Dodds et al. 2004). These methodological constraints limit our ability to develop a complete understanding of stream nutrient spiraling. To overcome these limitations, we propose a novel approach based on evidence from previous studies (Martí et al. 1997, von Schiller et al. 2011b) to infer 
$R$ by comparing $U_{\text {net }}$ and $U_{\text {gross }}$ estimated simultaneously from ambient and plateau longitudinal profiles obtained with short-term nutrient addition (Webster and Valett 2006).

The goals of our study were to apply our approach to estimate $R$ and its balance with $U_{\text {gross }}$ in headwater streams and to explore the temporal variability of $R$ and how changes in environmental conditions over time influence its relationship with $U_{\text {gross }}$. We analyzed a 2 -y data set from monthly solute additions of $\mathrm{NH}_{4}{ }^{+}$and soluble reactive P (SRP), essential sources of $\mathrm{N}$ and $\mathrm{P}$, in a perennial and an intermittent stream. In a previous study, we reported differences between streams in the temporal pattern of $U_{\text {gross }}$ that were partially explained by differences in the hydrological regimes of the streams (von Schiller et al. 2008). In the present study, we revisited this data set to infer $R$ and explore its temporal variation and its balance with $U_{\text {gross }}$ for the same streams and nutrients. Considering that most streams tend to be at short-term biogeochemical steady state, we predicted that the magnitude and temporal pattern of $R$ would follow that of $U_{\text {gross }}$ for both streams and nutrients. Furthermore, we predicted that occasional periods of imbalance between $R$ and $U_{\text {gross }}$ would occur more often at the intermittent than at the perennial stream because larger hydrological fluctuations at the former favor less-steadystate conditions. Our study sheds light on the relevance of release processes to in-stream nutrient spiraling and, thus, on their influence on downstream nutrient export.

\section{METHODS}

\section{Site description}

The Santa Fe stream $\left(2^{\text {nd }}\right.$-order; lat $2^{\circ} 27^{\prime} 40^{\prime \prime} \mathrm{E}$, long $41^{\circ} 46^{\prime}$ $\left.37^{\prime \prime} \mathrm{N}\right)$ and Fuirosos stream ( $3^{\text {rd }}$-order; lat $2^{\circ} 34^{\prime} 55^{\prime \prime} \mathrm{E}$, long $41^{\circ} 42^{\prime} 14^{\prime \prime} \mathrm{N}$ ) drain forested headwater catchments dominated by siliceous geology in natural protected areas in Catalonia (northeastern Spain). The catchments are only $10 \mathrm{~km}$ apart, but they experience contrasting climatic conditions because they are at different altitudes. The Santa Fe catchment $\left(2.6 \mathrm{~km}^{2}, 1419 \mathrm{~m}\right.$ asl $)$ has a Mediterranean subhumid climate with a mean annual precipitation of $\sim 1000 \mathrm{~mm}$ and mean annual temperature of $\sim 9^{\circ} \mathrm{C}$ (Ninyerola et al. 2000). The Fuirosos catchment $\left(14.4 \mathrm{~km}^{2}, 361 \mathrm{~m}\right.$ asl $)$ has a Mediterranean semiarid climate with a mean annual precipitation of $\sim 500 \mathrm{~mm}$ and mean annual temperature of $\sim 13^{\circ} \mathrm{C}$ (Ninyerola et al. 2000). Vegetation in the catchments and stream hydrology differ between the sites as a consequence of this climatic contrast. The Santa Fe catchment is dominated by mixed forests of coniferous (Abies alba) and deciduous (Fagus sylvatica) trees, whereas the Fuirosos catchment is dominated by evergreen perennial forests (Quercus suber, Pinus halepensis) at the lower elevations and deciduous forests (Castanea sativa, Corylus avellana, Quercus pubescens) at the higher elevations. Riparian vegetation at Santa Fe (F. sylvatica, Sambucus nigra) is poorly developed compared to that at Fuirosos (Alnus glutinosa, Platanus hispanica).

The Santa Fe stream (hereafter, perennial stream) has permanent flow, whereas the Fuirosos stream (hereafter, intermittent stream) has intermittent flow with summer periods of 0 flow of variable duration among years (from a few weeks to several months; Bernal et al. 2005, von Schiller et al. 2008, 2011a). Despite the strong differences in the hydrological regime, base flow is similar between streams (<20 L/s) (von Schiller et al. 2008). Water temperature tends to be lower in the perennial than in the intermittent stream because of the difference in altitude, but both streams show the same seasonal pattern of lower water temperature in winter than in summer (Bernal et al. 2005, von Schiller et al. 2008). Moreover, the streams differ markedly in the magnitude and temporal pattern of nutrient concentrations. $\mathrm{NO}_{3}{ }^{-}$dominates the dissolved inorganic $\mathrm{N}$ (DIN) pool in both streams, but it shows contrasting seasonal patterns between streams. The peak of $\mathrm{NO}_{3}{ }^{-}$occurs in summer in the perennial and in winter in the intermittent stream. The concentration of $\mathrm{NH}_{4}{ }^{+}$accounts for $<10 \%$ of DIN and shows no consistent seasonal pattern in either stream. The concentration of SRP is low in both streams $(<20 \mu \mathrm{g} \mathrm{P} / \mathrm{L})$, and it shows a marked seasonal pattern, similar to that of $\mathrm{NO}_{3}{ }^{-}$, only at the perennial stream. The DIN : SRP ratio is generally lower in the perennial than in the intermittent stream, and the intermittent stream shows higher DIN : SRP in winter than in summer.

\section{Field sampling and laboratory analyses}

We selected 1 representative stream reach at the perennial stream (140 m long) and at the intermittent stream (80 m long) at the mouth of each catchment. No lateral surface-water inputs were present along the stream reaches (for geomorphological details for each reach see von Schiller et al. 2008). In each stream reach, we conducted short-term constant-rate additions of SRP (as $\mathrm{NaH}_{2} \mathrm{PO}_{4}-2 \mathrm{H}_{2} \mathrm{O}$ ) and $\mathrm{NH}_{4}{ }^{+}$(as $\mathrm{NH}_{4} \mathrm{Cl}$ ) on a monthly basis from September 2004 to August 2006. The methods used for nutrient additions followed those of Webster and Valett (2006). Details on the nutrient-addition procedures at the 2 study sites were given by von Schiller et al. (2008). $\mathrm{Cl}^{-}$(as $\mathrm{NaCl}$ ) was added as a conservative tracer, and stream discharge $(Q, \mathrm{~L} / \mathrm{s})$ was estimated by recording conductivity changes over time at the bottom of the reach (Gordon et al. 2004). Before the additions, we collected water samples and measured conductivity (at $20^{\circ} \mathrm{C}$ ) at 8 locations along each of the 2 stream reaches (ambient concentrations). We measured wetted width ( $w$, in $\mathrm{m}$ ) at each sampling location and averaged values from all sampling locations to provide a mean value for the entire reach. When conductivity reached plateau at the bottom of the reach, we collected stream water samples at the same sampling locations (plateau concentrations). We per- 
formed all additions at baseflow conditions on a total of 25 and 20 sampling dates in the perennial and the intermittent stream, respectively.

We filtered water samples for nutrient chemistry immediately through precombusted glass-fiber filters $(0.7 \mu \mathrm{m})$, stored samples on ice in the field, and refrigerated them at $4^{\circ} \mathrm{C}$ or frozen in the laboratory until analysis. We analyzed water samples colorimetrically for $\mathrm{NH}_{4}^{+}$(salicylate method; Reardon et al. 1966) on a Skalar (Breda, The Netherlands) $\mathrm{San}^{+}$Autoanalyzer and for SRP (molybdate method; Murphy and Riley 1962) on a Bran+Luebbe (Norderstedt, Germany) TRAACS 2000 Autoanalyzer II.

\section{Calculation of in-stream processing fluxes}

Gross uptake. For each sampling date and nutrient, we calculated $U_{\text {gross }}\left(\mu \mathrm{g} \mathrm{N}\right.$ or $\mathrm{P} \mathrm{m}^{-2} \mathrm{~min}^{-1}$ ) using the nutrient concentration and conductivity values at plateau conditions corrected by ambient values following the calculation of nutrient uptake metrics based on the standard method of short-term nutrient additions (Webster and Valett 2006). $U_{\text {gross }}$ is an indicator of stream nutrient-retention capacity, and it integrates all uptake processes occurring along the reach, whether these are assimilatory or dissimilatory (Martí et al. 1997, Webster and Valett 2006). We estimated the gross uptake coefficient per unit of reach length $\left(k_{\text {gross }}\right.$, in $1 / \mathrm{m}$ ) using the following $1^{\text {st }}$-order equation

$$
C_{x}^{*}=C_{t o p}^{*}\left(\frac{\operatorname{Cond}_{x}^{*}}{\operatorname{Cond}_{t o p}^{*}}\right) e^{-k_{\text {gross }}}
$$

where $C^{*}$ is the plateau nutrient concentration corrected by the ambient concentration in stream water (in $\mu \mathrm{g} \mathrm{N} / \mathrm{L}$ or $\mu \mathrm{g} \mathrm{P} / \mathrm{L}$ ), and Cond* is the plateau stream-water conductivity corrected by the ambient conductivity (in $\mu \mathrm{S} / \mathrm{cm}$ ) at the top of the reach (top) and at each sampling location along the reach $(x$, in $\mathrm{m})$. Then, we calculated $U_{\text {gross }}$ as

$$
U_{\text {gross }}=\left(Q C_{\text {Avg }} k_{\text {gross }}\right) / w
$$

where $C_{A v g}$ is the average ambient nutrient concentration in stream water from the 8 sampling locations along the reach, and $w$ is the average wetted width. For each date, we estimated an upper and lower limit of $U_{\text {gross }}$ based on the previously calculated $95 \%$ confidence interval (CI) of $k_{\text {gross }}$.

Measurements of $k_{\text {gross }}$ and $U_{\text {gross }}$ can be underestimated during solute-addition experiments because of nutrient enrichment effects (Mulholland et al. 2002). To minimize this effect, we adjusted the nutrient concentration of the added solution and the pump flow rate for each addition to reach a relatively low and similar nutrient-enrichment level among addition dates and streams. In the perennial stream, in- creases in nutrient concentration relative to ambient nutrient concentration at the top sampling station (mean \pm SE) were $54 \pm 9 \mu \mathrm{g} \mathrm{N} / \mathrm{L}$ for $\mathrm{NH}_{4}{ }^{+}$and $65 \pm 8 \mu \mathrm{g} \mathrm{P} / \mathrm{L}$ for SRP. In the intermittent stream, these increases were $65 \pm 14 \mu \mathrm{g}$ $\mathrm{N} / \mathrm{L}$ for $\mathrm{NH}_{4}{ }^{+}$and $79 \pm 16 \mu \mathrm{g} \mathrm{P} / \mathrm{L}$ for SRP. We found only a negative, but weak, correlation between the nutrient enrichment and $k_{\text {gross }}$ for $\mathrm{NH}_{4}{ }^{+}$in the intermittent stream (Pearson product-moment correlation: $r=-0.48, p=0.032, n=$ 20), which suggests that overall our estimates of $U_{\text {gross }}$ were minimally affected by nutrient enrichment.

Net uptake. For each sampling date and nutrient, we calculated $U_{n e t}$ from the longitudinal variation in ambient nutrient concentration along the stream reach following the spiraling method described by von Schiller et al. (2011b). First, we estimated the net uptake coefficient per unit of reach length $\left(k_{\text {net }}\right.$, in $\left.1 / \mathrm{m}\right)$ using the $1^{\text {st }}$-order equation

$$
C_{x}=C_{t o p}\left(\frac{\operatorname{Cond}_{x}}{\operatorname{Cond}_{t o p}}\right) e^{-k_{n e t^{x}}}
$$

where $C$ is stream-water ambient nutrient concentration (in $\mu \mathrm{g} \mathrm{N} / \mathrm{L}$ or $\mu \mathrm{g} \mathrm{P} / \mathrm{L}$ ) and Cond is ambient stream-water conductivity (in $\mu \mathrm{S} / \mathrm{cm}$ ) at the top of the reach (top) and at each sampling location along the reach $(x$, in $\mathrm{m})$. We calculated $k_{\text {net }}$ and its $\pm 95 \%$ CI from the regression between the natural logarithm of the stream-water nutrient concentration corrected by conductivity and the downstream distance $(x)$ after linearizing Eq. 3.

Then, we calculated $U_{\text {net }}$ based on Eq. 2 , but in this case we used $k_{\text {net }}$ instead of $k_{\text {gross }}$. $U_{\text {net }}$ integrates nutrient uptake and release processes occurring along the reach and can be positive (uptake $>$ release), negative (uptake $<$ release) or 0 (uptake $\approx$ release) depending on the value of $k_{\text {net }}$. For each date, we estimated an upper and lower limit of $U_{\text {net }}$ based on the $95 \% \mathrm{CI}$ of $k_{\text {net }}$. We assumed that $U_{\text {net }}$ was indistinguishable from 0 (uptake $\approx$ release) when its CI contained 0 (von Schiller et al. 2011b).

Beyond the convenience of using the same mathematical approach for calculating $U_{\text {gross }}$ and $U_{\text {net }}$, estimating $U_{\text {net }}$ with the spiraling method has a number of advantages compared to the more commonly used mass-balance method (e.g., Roberts and Mulholland 2007). The spiraling method is based on a $1^{\text {st }}$-order reaction model, which is likely to be more representative of in-stream nutrient dynamics than the linear model used in the mass-balance method (Newbold et al. 1981, Webster and Valett 2006). Furthermore, the spiraling method is based on a whole-reach integrative measure of a consistent concentration trend across several sampling points rather than on the change in nutrient load between only 2 sampling points as it is for the mass-balance method. Thus, the spiraling method is more conservative and less prone than the mass-balance approach to overestimate those cases in which there is net uptake or release, 
especially for highly reactive nutrients, such as $\mathrm{NH}_{4}{ }^{+}$or SRP (von Schiller et al. 2011b). Moreover, a common limitation of the 2 methods used for estimating $U_{n e t}$ is the uncertainty associated with the groundwater inputs. $U_{n e t}$ estimates with the spiraling method are based on changes in nutrient concentration rather than on changes in nutrient mass, so the spiraling method minimizes the influence of either groundwater inputs or stream-water losses on the calculation compared to the mass-balance method (Payn et al. 2009). The magnitude of groundwater discharge is relatively easy to measure with conservative tracer additions. On the contrary, reliable groundwater concentration measurements are difficult to obtain, mainly because they are highly variable over small spatial scales (Lewis et al. 2006) and because concentration might differ between groundwater collected from piezometers and water at the interface between the ground and surface water, which is the water that finally enters the stream (Brookshire et al. 2009). Groundwater nutrient concentrations and fluxes are not required when applying the spiraling method, but small (or almost negligible) groundwater inputs and similar concentrations between groundwater and surface water are the 2 conditions that must be fulfilled to obtain reliable measurements of $U_{\text {net }}$ with this empirical approach (von Schiller et al. 2011b). We evaluated the suitability of the spiraling method in our study streams by assessing the contribution of groundwater inputs to stream discharge along the study reaches from changes in ambient-corrected conductivity along the reach at plateau conditions (Gordon et al. 2004). Moreover, we compiled available data of $\mathrm{NH}_{4}{ }^{+}$and SRP concentrations in near-stream ground water $(<5 \mathrm{~m}$ from the stream channel) from the period 2004-2012 to examine differences in nutrient concentrations between ground water and surface stream water. Additional details on the assumptions and limitations and a sensitivity analysis of the spiraling method and its comparison with the mass-balance method were published by von Schiller et al. (2011b).

Release. We calculated $R$ (in $\mu \mathrm{g} \mathrm{N}$ or $\mathrm{P} \mathrm{m}^{-2} \mathrm{~min}^{-1}$ ) along the reach for each sampling date and nutrient as

$$
R=U_{\text {gross }}-U_{\text {net }}
$$

Like $U_{\text {gross }}$, this method cannot be used to distinguish among specific biogeochemical processes involved in the release of dissolved inorganic nutrients from the active stream bed to the water column. Therefore, $R$ for $\mathrm{NH}_{4}{ }^{+}$ accounts for those $\mathrm{NH}_{4}{ }^{+}$molecules returning to the water column via several processes, including ammonification, desorption from organic and inorganic sediments, or dissimilatory $\mathrm{NO}_{3}{ }^{-}$reduction to $\mathrm{NH}_{4}{ }^{+}$(Fig. 1A). Similarly, $R$ for SRP accounts for those SRP molecules returning to the water column via mineralization, desorption, or dissolution reactions (Fig. 1A).
For each sampling date and nutrient, we calculated the CI of $R\left(\mathrm{CI}_{R}\right)$ by propagating the uncertainty associated with $U_{\text {gross }}$ and $U_{\text {net }}$ estimates as

$$
\mathrm{CI}_{R}=\sqrt{\mathrm{CI}_{\text {gross }}^{2}+\mathrm{CI}_{\text {net }}^{2}}
$$

where $\mathrm{CI}_{\text {gross }}$ and $\mathrm{CI}_{\text {net }}$ are the CIs for $U_{\text {gross }}$ and $U_{\text {net }}$, respectively (Zar 2010). $R$ can be positive or $0 . R>0$ occurs when $U_{\text {gross }}>U_{\text {net }}$, and the lower and upper limits of $\mathrm{CI}_{R}$ are $>0 . R>0$ occurs when $U_{\text {gross }} \approx U_{\text {net }}$ or when the lower limit of $\mathrm{CI}_{R}$ is $<0$. By definition, $R<0$ has no ecological meaning. In fact, 95\% of the estimated $R$ values (43 of 45) in our study matched the criterion of $R \geq 0$. The 2 cases for which estimated $R<0$ were removed from the data set and were not included in the data analysis. Even if a small enrichment effect may have occurred during nutrientaddition experiments, both $U_{g r o s s}$ and $R$ would have been underestimated to the same extent; thus, their temporal pattern and the balance between them would not have changed.

\section{Data analysis}

$R, U_{\text {gross }}$, and $U_{\text {net }}$ data were grouped into different hydrological periods that have a strong influence on stream hydrology, nutrient availability, and $U_{\text {gross }}$ in both study sites (von Schiller et al. 2008). For the perennial stream, we divided each hydrological year into 2 periods: 1) from December to April (the cool-wet and dormant period, hereafter wet period), and 2) from May to November (the warmdry and vegetative period, hereafter $d r y$ period). Because of the influence of drought on stream hydrology and nutrient availability (von Schiller et al. 2011a), the data set for the intermittent stream was divided into 3 hydrological periods: 1) from December to mid-March (the cool-wet and dormant season, hereafter wet period), 2) from midMarch to August (the warm-dry and vegetative period, hereafter dry period), and 3) from September to November (the transition from dry to wet conditions, hereafter transition period) (von Schiller et al. 2008).

We used independent $t$-tests to compare nutrient concentrations between ground water and surface water. We used independent $t$-tests to compare in-stream $R, U_{\text {gross }}$, and $U_{\text {net }}$ between streams, and dependent $t$-tests to compare the same variables between nutrients in each stream. To assess differences in in-stream processing fluxes between different hydrological periods we used 1-way analysis of variance (ANOVA). When differences were statistically significant, we applied a post hoc Tukey test to identify differences between pairs of groups. We tested for the statistical differences in the proportion of dates with $R>0$ and $U_{\text {net }}$ $\neq 0$ between nutrients and streams by applying a $2 \times 2$ contingency-table analysis (Zar 2010). To evaluate the degree of coupling between $U_{\text {gross }}$ and $R$ we used Pearson product-moment correlation analysis between the 2 vari- 
ables for each nutrient and stream separately. To quantify the divergences from the $1: 1$ line $\left(R=U_{\text {gross }}\right)$ we calculated the relative root mean-square error (RRMSE, in \%) for each nutrient and stream as

$$
\text { RRMSE }=\frac{\sqrt{\sum_{i=1}^{n}\left(U_{\text {gross }, i}-R_{i}\right)^{2}}}{n \overline{U_{\text {gross }}}} \times 100
$$

where $n$ is the total number of observations and $\overline{U_{\text {gross }}}$ is the average value of $U_{\text {gross }}$. Low values of RRMSE indicate high coupling between $U_{\text {gross }}$ and $R$, whereas high values indicate the opposite. All statistical analyses were done with Statistica (version 6.0; StatSoft, Tulsa, Oklahoma). In all cases, differences were considered significant if $p<0.05$.

\section{RESULTS}

Longitudinal trends of conductivity at plateau revealed low influence of groundwater inflow. We observed either small net increases or constant discharge along the reach in both streams on all sampling dates (Fig. 2A). The \% contribution of ground water to stream discharge along the reach (mean $\pm \mathrm{SE}$ ) was $17.0 \pm 1.4 \%$ in the perennial stream and $11.9 \pm 2.9 \%$ in the intermittent stream. In addition, groundwater concentrations of $\mathrm{NH}_{4}{ }^{+}$and SRP were low and did not differ from those measured in the water column in both streams ( $t$-tests, $p>0.05$; Fig. $2 \mathrm{~B}, \mathrm{C}$ ) except that mean SRP concentration in the perennial stream was $1.5 \times$ higher in ground water than in surface water $(t$-test, $p=0.036)$

On average, $R$ and $U_{\text {gross }}$ values were higher in the perennial than in the intermittent stream, and within each stream, they were higher for $\mathrm{NH}_{4}{ }^{+}$than for SRP (Table 1). Mean $U_{\text {net }}$ values were low but positive, except for SRP in the intermittent stream, and they were similar between nutrients within each stream (Table 1). Mean $U_{\text {net }}$ for $\mathrm{NH}_{4}{ }^{+}$was similar between the perennial and the intermittent streams, whereas mean $U_{n e t}$ for SRP was higher in the perennial than in the intermittent stream (Table 1).

The temporal patterns of $R, U_{\text {gross }}$, and $U_{n e t}$ differed substantially between streams and nutrients (Figs 3A, B, 4A, B). In the perennial stream, $R$ and $U_{\text {gross }}$ for $\mathrm{NH}_{4}{ }^{+}$did not differ between the wet and dry periods ( $p>0.05$; Fig. 3A), but for SRP, both were higher during the dry than during the wet periods $\left(F_{1,23}=9.709\right.$ and 8.780, $p=0.005$ and 0.007 for $R$ and $U_{\text {gross }}$, respectively; Fig. $\left.3 \mathrm{~B}\right)$. Conversely, $U_{\text {net }}$ showed no difference between hydrological periods for either nutrient ( $p>0.05$; Fig. 3A, B). In the intermittent stream, $R, U_{\text {gross }}$, and $U_{\text {net }}$ for $\mathrm{NH}_{4}{ }^{+}$showed no consistent temporal pattern $(p>0.05$; Fig. $4 \mathrm{~A})$. However, $R$ and $U_{\text {net }}$ for SRP differed significantly among hydrological periods $\left(F_{2,16}=4.374\right.$ and $4.555, p=0.031$ and 0.027 for $R$ and $U_{n e t}$, respectively), and were higher during the wet than during the dry and transition periods (Tukey test, $p<0.05$; Fig. 4B).
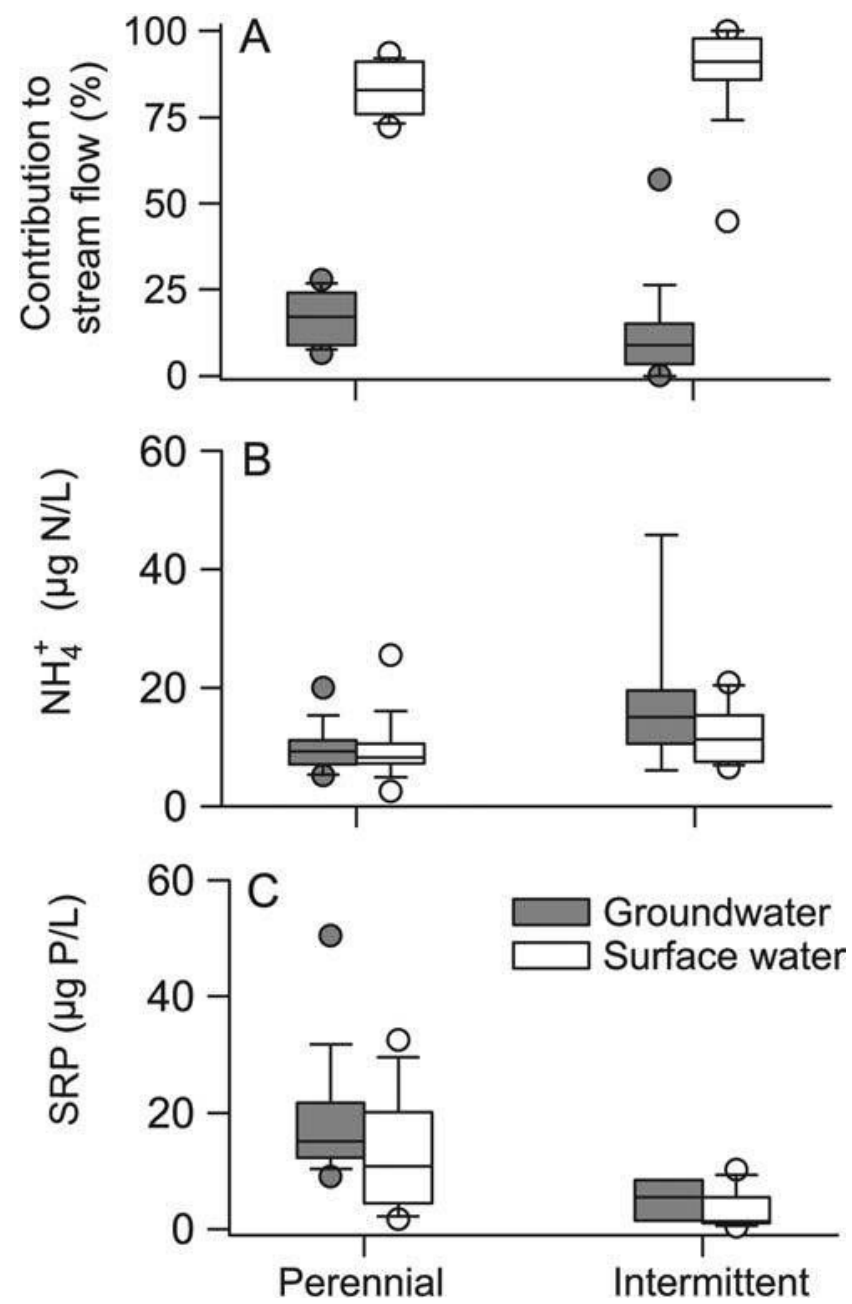

Figure 2. Box plots of the contribution of ground water and surface water to stream discharge in the study reaches $(\mathrm{A})$ and of their concentration of $\mathrm{NH}_{4}{ }^{+}$(B) and soluble reactive $\mathrm{P}$ $(\mathrm{SRP})(\mathrm{C})$. Box plots display $10^{\text {th }}$ and $90^{\text {th }}$ (whiskers), $25^{\text {th }}$ and $75^{\text {th }}$ (box ends), and $50^{\text {th }}$ (line) percentiles, and outliers (circles). The data set for discharge and stream water concentrations is from monthly samplings during the study period $(n=25$ and $n=20$ in the perennial and the intermittent stream, respectively). The data set for groundwater concentrations is from sporadic measurements during the period 2004-2012 (perennial stream: $n=21$ for both nutrients; intermittent stream: $n=13$ and $n=4$ for $\mathrm{NH}_{4}{ }^{+}$and SRP, respectively).

$U_{\text {gross }}$ for SRP did not show a consistent temporal pattern ( $p>0.05$; Fig. 4B).

The frequency of in-stream release and net uptake also differed between streams and nutrients. The proportion of dates with $R>0$ was greater in the perennial than in the intermittent stream for $\mathrm{NH}_{4}^{+}\left(84\right.$ vs $\left.37 \%, \chi^{2}=10.4, p<0.005\right)$ and SRP ( 88 vs $58 \%, \chi^{2}=5.2, p<0.05$ ). We found no differences in the frequency of $R>0$ between nutrients within each stream $\left(\chi^{2}<1.7, p>0.05\right)$. Moreover, the proportion of dates for which $R$ and $U_{\text {gross }}$ did not counterbalance each other $\left(U_{\text {net }} \neq 0\right)$ was similar between the perennial stream 
Table 1. Mean \pm SE (in $\mu \mathrm{g} \mathrm{N}$ or $\mathrm{P} \mathrm{m}^{-2} \mathrm{~min}^{-1}$ ) of in-stream release $(R)$, gross uptake $\left(U_{\text {gross }}\right)$, and net uptake $\left(U_{\text {net }}\right)$ for each stream and nutrient. $n=25$ and 19 in the perennial and the intermittent stream, respectively. SRP $=$ soluble reactive P. $p$-values are results from $t$-tests between nutrients within streams and between streams. Bold indicates $p<0.05$.

\begin{tabular}{|c|c|c|c|c|c|c|}
\hline \multirow[b]{2}{*}{ Variable } & \multirow[b]{2}{*}{ Nutrient } & \multicolumn{2}{|c|}{ Perennial stream } & \multicolumn{2}{|c|}{ Intermittent stream } & \multirow[b]{2}{*}{ Between-stream $p$} \\
\hline & & Mean $\pm \mathrm{SE}$ & Between-nutrient $p$ & Mean \pm SE & Between-nutrient $p$ & \\
\hline \multirow[t]{2}{*}{$R$} & $\mathrm{NH}_{4}^{+}$ & $29.8 \pm 4.3$ & $<0.001$ & $14.3 \pm 2.9$ & 0.003 & 0.008 \\
\hline & SRP & $8.2 \pm 1.4$ & & $3.8 \pm 0.8$ & & 0.014 \\
\hline \multirow[t]{2}{*}{$U_{\text {gross }}$} & $\mathrm{NH}_{4}^{+}$ & $31.1 \pm 4.0$ & $<0.001$ & $14.4 \pm 3.2$ & $<0.001$ & 0.001 \\
\hline & SRP & $8.5 \pm 1.5$ & & $1.6 \pm 0.3$ & & $<0.001$ \\
\hline \multirow[t]{2}{*}{$U_{n e t}$} & $\mathrm{NH}_{4}^{+}$ & $1.3 \pm 1.7$ & 0.626 & $0.04 \pm 1.2$ & 0.086 & 0.564 \\
\hline & SRP & $0.3 \pm 0.6$ & & $-2.2 \pm 0.9$ & & 0.020 \\
\hline
\end{tabular}

and the intermittent stream for $\mathrm{NH}_{4}^{+}\left(36 \mathrm{vs} 21 \% ; \chi^{2}=1.2\right.$, $p>0.05$ ) and for SRP (56 vs $68 \% ; \chi^{2}=0.7, p>0.05$ ). Differences were observed between nutrients only in the intermittent stream where the frequency of $U_{\text {net }} \neq 0$ was higher for SRP than for $\mathrm{NH}_{4}{ }^{+}\left(\chi^{2}=8.6, p<0.005\right)$.

For both streams and nutrients, $R$ and $U_{\text {gross }}$ were significantly correlated (Pearson product-moment correlation, $p<0.05)$ and fell close to the $1: 1$ line, showing low RRMSE values $(<10 \%)$ despite the broad range of variation for the 2 metrics (Fig. 5A-D). The exception was SRP in the intermittent stream, which showed a strong decoupling between the 2 spiraling metrics (Pearson product-moment correlation, $p=0.966$, RRMSE $=62 \%$ ), especially during the wet period when $R>U_{\text {gross }}$ (Fig. 5D).

\section{DISCUSSION}

We used a novel approach to explore the temporal variation of in-stream $R$ and how it relates to in-stream $U_{\text {gross }}$ in data derived from solute additions in 2 headwater streams with contrasting hydrological regimes. We observed remarkable temporal variation of $R$ and found that the magnitude of $R$ and $U_{\text {gross }}$ tended to be similar, leading to $U_{\text {net }} \approx 0$ on numerous sampling dates (from $60-80 \%$ and $30-40 \%$ for $\mathrm{NH}_{4}{ }^{+}$and SRP, respectively). These results are consistent with the idea that streams can be highly reactive ecosystems with high biogeochemical processing rates (Peterson et al. 2001, Mulholland et al. 2008) while approaching short-term biogeochemical steady-state for dissolved inorganic nutrient fluxes (Brookshire et al. 2009).

Furthermore, our results illustrate that changes in environmental conditions over time can lead to transitory periods during which $R$ and $U_{\text {gross }}$ are in disequilibrium. Our results are in line with results of studies in which biogeochemical processing in headwater streams was able to regulate to some extent (4-40\%) annual nutrient export during baseflow conditions because $U_{\text {net }}$ is not always 0 over time (Bernal et al. 2012). Our results also are in line with those of studies showing that streams can act as net sinks or sources of dissolved inorganic nutrients in response to profound changes in either hydromorphological conditions or resource availability. For instance, $\mathrm{N}$ tended to accumulate as algal biomass after floods in a desert stream, clearly illustrating a case in which $U_{\text {gross }}>R$ (Grimm 1987, Martí et al. 1997).

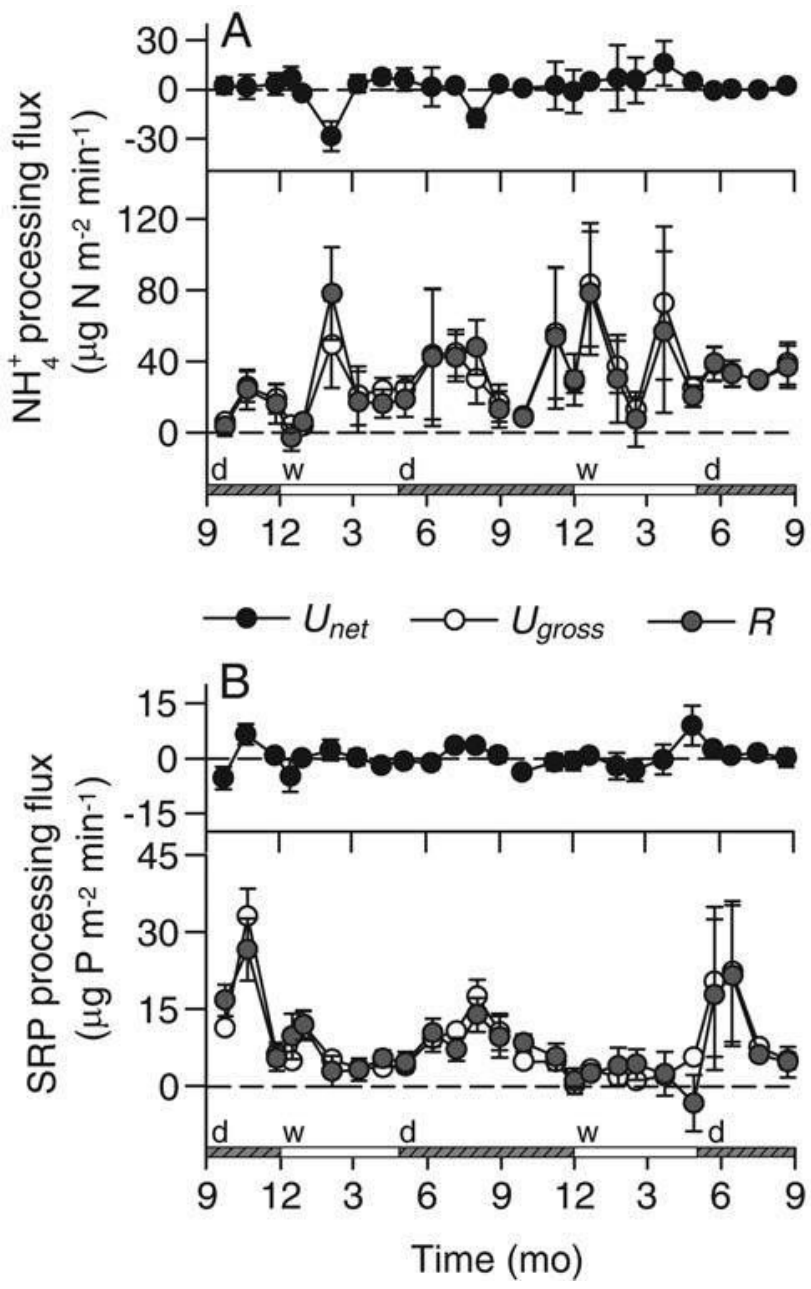

Figure 3. Mean $( \pm 95 \% \mathrm{CI})$ in-stream net uptake $\left(U_{\text {net }}\right)$, gross uptake $\left(U_{\text {gross }}\right)$, and release $(R)$ for $\mathrm{NH}_{4}{ }^{+}(\mathrm{A})$ and soluble reactive $\mathrm{P}(\mathrm{SRP})(\mathrm{B})$ in the perennial stream during the study period. The 0 line is indicated with a dashed line. Different hydrological periods are indicated with different shadings in the horizontal bar $(\mathrm{d}=$ dry period, $\mathrm{w}=$ wet period). 

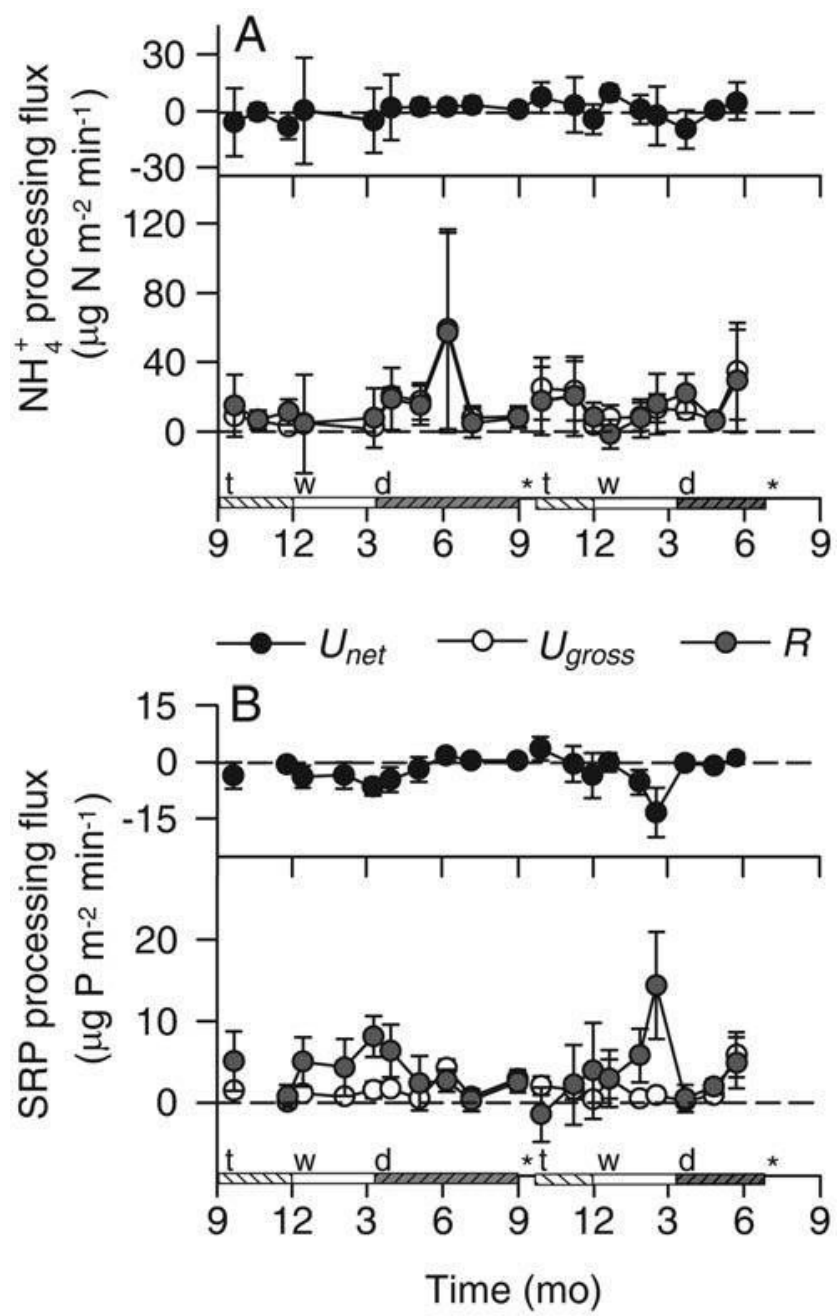

Figure 4. Mean $( \pm 95 \% \mathrm{CI})$ in-stream net uptake $\left(U_{\text {net }}\right)$, gross uptake $\left(U_{\text {gross }}\right)$, and release $(R)$ for $\mathrm{NH}_{4}{ }^{+}(\mathrm{A})$ and soluble reactive $\mathrm{P}(\mathrm{SRP})(\mathrm{B})$ in the intermittent stream during the study period. The 0 line is indicated with a dashed line. Different hydrological periods are indicated with different shadings in the horizontal bar $(\mathrm{d}=$ dry period, $\mathrm{w}=$ wet period, $\mathrm{t}=$ transition period $)$. Asterisks (*) indicate periods of 0 flow.

Similarly, high organic matter availability during autumn or high light irradiance before leafout in spring can enhance in-stream net $\mathrm{N}$ immobilization (Mulholland 2004, Roberts and Mulholland 2007). Furthermore, high in-stream denitrification in macrophyte-dominated rivers also can lead to increased net $\mathrm{N}$ uptake (Heffernan et al. 2010). Doyle et al. (2003) showed that removal of a dam strongly modified geomorphology of a $5^{\text {th }}$-order stream and led to decreased net $\mathrm{P}$ uptake fluxes, probably because of changes in the balance between $U_{\text {gross }}$ and $R$.

According to ecological succession theory (Vitousek and Reiners 1975), in-stream uptake and release processes should vary over successional time after hydrological disturbances. At early successional stages, $R<U_{\text {gross }}$
( $\left.U_{\text {net }}>0\right)$ should be expected, whereas $R \approx U_{\text {gross }}\left(U_{\text {net }} \approx\right.$ 0 ) may occur at late successional stages (Grimm 1987, Martí et al. 1997). In this context, we predicted that the intermittent stream would experience more frequent periods of imbalance between $R$ and $U_{\text {gross }}$ than the perennial stream because larger hydrological fluctuations at the former may favor less-steady-state conditions. In fact, dramatic changes in the temporal pattern of water chemistry, algal composition, organic matter accumulation, stream metabolism, and nutrient retention efficiency have been reported after hydrological disturbances in the intermittent stream (Acuña et al. 2004, von Schiller et al. 2008, Bernal et al. 2013). Nonetheless, our results did not support our prediction. First, periods of imbalance (frequency of $U_{\text {net }}$ $\neq 0$ ) were similar between the intermittent and perennial stream for SRP and $\mathrm{NH}_{4}{ }^{+}$. The prevalence of $R>U_{\text {gross }}$ for SRP measured in the intermittent stream during the wet period (see below) was unrelated to the occurrence of any extreme hydrological event. Moreover, the theoretical expectation is that after disturbances, $U_{\text {gross }}$ should prevail over $R$ (Grimm 1987). Sampling the streams only in baseflow conditions and at monthly intervals may have prevented us from capturing potential successional changes, which can occur very rapidly in stream ecosystems, especially in highly resilient ecosystems, such as headwater streams (Grimm 1987, Martí et al. 1997, Uehlinger 2000). Further studies monitoring net uptake and release processes after extreme flood or drought events are needed to understand changes in in-stream nutrient cycling during ecosystem succession and the stability of these ecosystems before hydrological disturbances.

We observed consistent biogeochemical disequilibrium for SRP in the intermittent stream with $R>U_{\text {gross }}$ during most of the wet period. One possible explanation for such increased $R$ over $U_{\text {gross }}$ could be desorption of $\mathrm{P}$ from stream sediments, which typically occurs when dissolved P concentrations in stream water and sediments are not in equilibrium (Reddy et al. 1995). The extremely low SRP concentrations in the intermittent stream during the wet period ( $<5 \mu \mathrm{g}$ P/L, von Schiller et al. 2008) supports the idea that $\mathrm{P}$ desorption from stream sediments could be at least partially responsible for the observed in-stream SRP release. High molar DIN : SRP (mean = 1638) measured during the wet period in the intermittent stream further suggests that $P$ release may result from an abiotic rather than a biotic process because such relatively low $\mathrm{P}$ availability may be limiting ecosystem production (Borchardt 1996). Unfortunately, no data on $\mathrm{P}$ concentration in the interstitial water of stream sediments are available for the study period to test the desorption hypothesis. In any case, our observations open an intriguing question that could be addressed in future studies specifically designed to test the mechanisms driving the high release of $\mathrm{P}$ observed in the intermittent stream. 

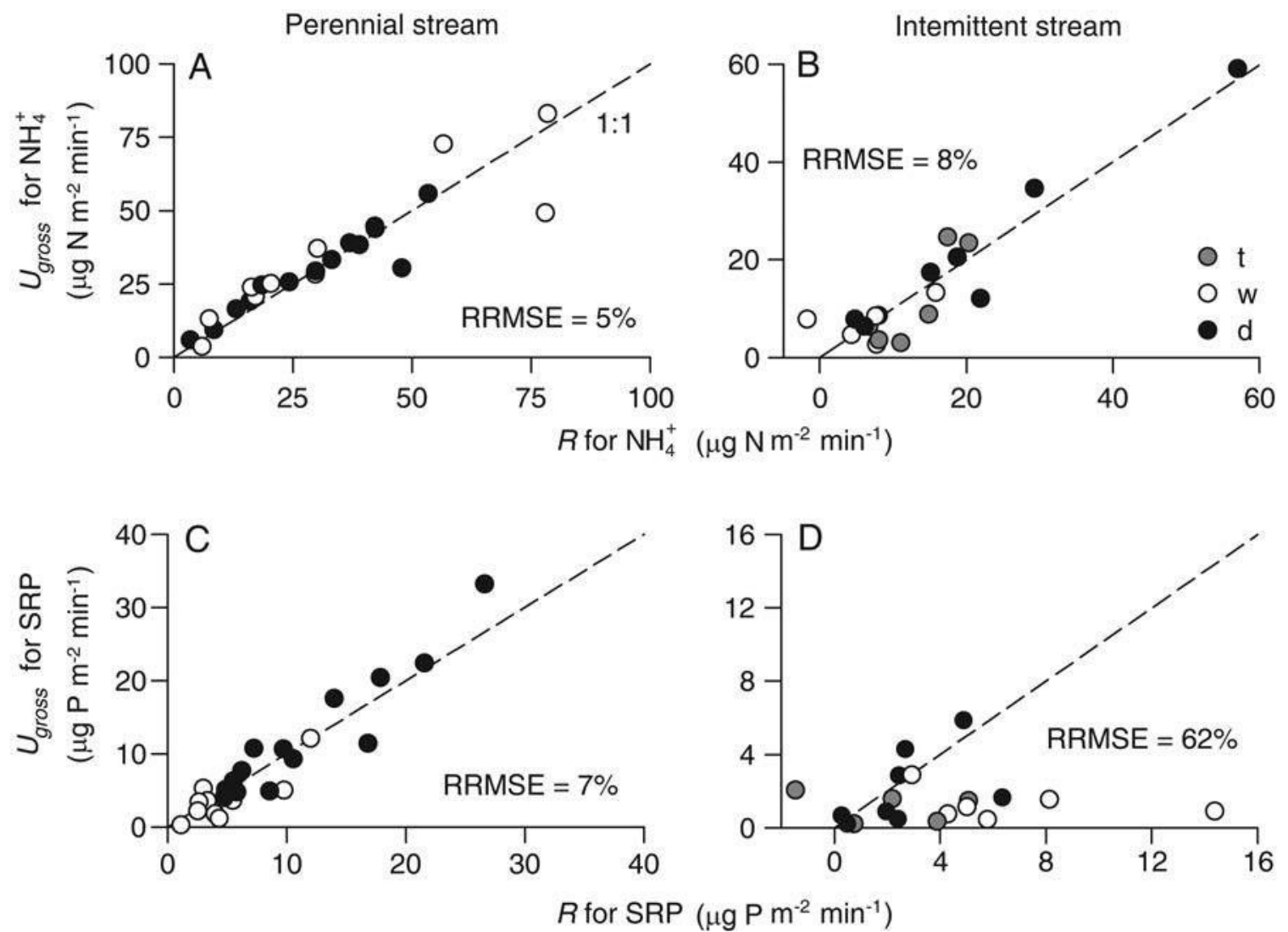

Figure 5. Relationship between in-stream gross uptake $\left(U_{\text {gross }}\right)$ and release $(R)$ for $\mathrm{NH}_{4}{ }^{+}(\mathrm{A}, \mathrm{B})$ and SRP $(\mathrm{C}, \mathrm{D})$ in the perennial stream $(\mathrm{A}, \mathrm{C})$ and the intermittent stream $(\mathrm{B}, \mathrm{D})$. Hydrological periods $(\mathrm{d}=$ dry period, $\mathrm{w}=$ wet period, $\mathrm{t}=$ transition period $)$ are marked with different shading. The $1: 1$ line (dashed line) and the relative root mean-square error (RRMSE) are shown in each panel.

A major limitation when dealing with the empirical estimation of in-stream biogeochemical rates and fluxes is the unknowns associated with groundwater nutrient inputs, especially when calculating $U_{n e t}$. The mass-balance and nutrient-spiraling methods used to estimate $U_{\text {net }}$ incorporate the uncertainty associated with groundwater sources in their calculations, albeit in different ways, and each of the 2 approaches has its pros and cons (see Methods and von Schiller et al. 2011b). In particular, the spiraling method assumes that groundwater nutrient concentrations change proportionally to changes in stream-water conductivity along the reach, an assumption that may not hold across streams and that is difficult to test in the field. However, the influence of groundwater inputs on the estimation of $U_{\text {net }}$ remains low if the groundwater inflow is small and nutrient concentrations in ground water and surface water are similar (von Schiller et al. 2011b). Thus, one way to evaluate the feasibility of applying the spiraling method to a particular study site is to collect near-stream groundwater samples prior to nutrient-addition experiments. For our study sites, groundwater inflow was low (mean $<18 \%$ ), and the concentration of $\mathrm{NH}_{4}{ }^{+}$and SRP was similar between ground water and surface water (mean groundwater: surface water ratio $<1.7$ ). These data provided empirical evi- dence that the influence of ground water on the estimates of $U_{n e t}$ was relatively small. As an example, we used the estimated $Q$, the groundwater inflow along the reach, and the SRP concentrations at the top and bottom of the reach to calculate the groundwater SRP concentration needed to fully explain the high $R$ values measured for SRP at the intermittent stream during the wet period. Our mass balance calculation indicates that the SRP concentration (mean $\pm \mathrm{SE}, n=5$ ) should be $22.7 \pm 4.5$-fold higher in ground water than in surface water to account for the detected release of SRP. This value is well above the groundwater: surface water ratio for SRP concentration in the intermittent stream (mean $=1.6, n=4)$. Thus, we think it is reasonable to conclude that the positive $R$ for SRP during the wet period in the intermittent stream resulted mostly from in-stream biogeochemical processing.

Despite the practical limitations inherent to any empirical approach dealing with open and complex natural systems, we think that the empirical approach used in our study is an advance toward a better understanding of the full round trip of nutrients along the spiral in streams. In particular, our results allowed us to shed light on the contribution of in-stream release processes to nutrient spiraling and on its temporal dynamics, an unknown aspect in stream 
ecology (Mulholland and Webster 2010). Our approach cannot be used to distinguish between the different biogeochemical processes involved in in-stream nutrient uptake (e.g., assimilation, sorption) and release (e.g., mineralization, desorption), but it can be used to quantify the relative importance of those fluxes and their temporal dynamics. In addition, it is a field method based on the well founded nutrient spiraling theory, is fairly simple and affordable, and is easy to repeat over time (e.g., in studies of temporal variability). Another appealing feature of this approach is that $R$ values could be estimated by revisiting data from many already existing data sets based on stream nutrient additions performed worldwide, when information on groundwater inputs is available for evaluating the feasibility of applying the spiraling method. This exercise would undoubtedly broaden our understanding of the balance between $U_{\text {gross }}$ and $R$ and of the environmental factors controlling them (Ensign and Doyle 2006). $\mathrm{NH}_{4}{ }^{+}$and SRP, the 2 reactive forms of $\mathrm{N}$ and $\mathrm{P}$ we studied, are essential nutrients for stream production, but a complete understanding of $\mathrm{N}$ and $\mathrm{P}$ spiraling in stream ecosystems may further include organic N and P cycling in streams (Johnson et al. 2013). Nevertheless, our study highlights that in-stream release processes can be highly variable in time and play a pivotal role in nutrient cycling, at least for $\mathrm{NH}_{4}{ }^{+}$and SRP in the study streams during baseflow conditions. Our results imply that the balance (or imbalance) between in-stream gross nutrient uptake and release rather than in-stream gross nutrient uptake alone could provide highly valuable information for a better understanding of the actual role of stream ecosystems as sources or sinks of nutrients.

\section{ACKNOWLEDGEMENTS}

We thank A. Argerich, P. Fonollà, and S. Pla for field and laboratory assistance and M. Peipoch, A. Argerich, and E. Vázquez for providing groundwater data. We also are grateful to M. Ribot for helpful comments on a previous version of the manuscript and to the directors of the Natural Parks of Montseny and MontnegreCorredor (Diputació de Barcelona) for allowing access to the sampling sites. DvS and SB were funded by the Spanish Ministry of Economy and Competitiveness (MINECO) with Juan de la Cierva contracts JCI-2010-06397 and JCI-2008-1777. SB received additional funds from the Spanish Research Council (CSIC) with the contract JAEDOC027. Financial support was provided by the European Union-funded projects EURO-LIMPACS (GOCE-CT2003-505540) and REFRESH (FP7-ENV-2009-1-244121) and the MINECO-funded projects SCARCE-Consolider (CSD 2009-00065), MONTES-Consolider (CSD 2008-00040), and MED_FORESTREAM (CGL2011-30590).

\section{LITERATURE CITED}

Acuña, V., A. Giorgi, I. Muñoz, U. Uehlinger, and S. Sabater. 2004. Flow extremes and benthic organic matter shape the metabolism of a headwater Mediterranean stream. Freshwater Biology 49:960-971.
Bernal, S., A. Butturini, and F. Sabater. 2005. Seasonal variations of dissolved nitrogen and DOC:DON ratios in an intermittent Mediterranean stream. Biogeochemistry 75:351-372.

Bernal, S., D. von Schiller, E. Martí, and F. Sabater. 2012. Instream net uptake regulates inorganic nitrogen export from catchments under base flow conditions. Journal of Geophysical Research 117:G00N05.

Bernal, S., D. von Schiller, F. Sabater, and E. Martí. 2013. Hydrological extremes modulate nutrient dynamics in mediterranean climate streams across different spatial scales. Hydrobiologia 719:31-42.

Borchardt, M. A. 1996. Nutrients. Pages 183-227 in R. J. Stevenson, M. L. Lowe, and R. L. Bothwell (editors). Algal ecology. Academic Press, San Diego, California.

Brookshire, E., H. Valett, and S. Gerber. 2009. Maintenance of terrestrial nutrient loss signatures during in-stream transport. Ecology 90:293-299.

Dodds, W. K., E. Martí, J. L. Tank, J. Pontius, S. K. Hamilton, N. B. Grimm, W. B. Bowden, W. H. McDowell, B. J. Peterson, H. M. Valett, J. R. Webster, and S. Gregory. 2004. Carbon and nitrogen stoichiometry and nitrogen cycling rates in streams. Oecologia (Berlin) 140:458-467.

Doyle, M. W., E. H. Stanley, and J. M. Harbor. 2003. Hydrogeomorphic controls on phosphorus retention in streams. Water Resources Research 39. doi:10.1029/2003WR002038

Ensign, S. H., and M. W. Doyle. 2006. Nutrient spiraling in streams and river networks. Journal of Geophysical Research: Biogeosciences 111. doi:10.1029/2005JG000114

Gordon, N. D., T. A. McMahon, and B. L. Finlayson. 2004. Stream hydrology: an introduction for ecologists. Wiley, West Sussex, UK.

Grimm, N. B. 1987. Nitrogen dynamics during succession in a desert stream. Ecology 68:1157-1170.

Heffernan, J. B., M. J. Cohen, T. K. Frazer, R. G. Thomas, T. J. Rayfield, J. Gulley, J. B. Martin, J. J. Delfino, and W. D. Graham. 2010. Hydrologic and biotic influences on nitrate removal in a subtropical spring-fed river. Limnology and Oceanography $55: 249-263$.

Johnson, L. T., J. L. Tank, R. O. Hall, P. J. Mulholland, S. K. Hamilton, H. M. Valett, J. R. Webster, M. J. Bernot, W. H. McDowell, B. J. Peterson, and S. M. Thomas. 2013. Quantifying the production of dissolved organic nitrogen in headwater streams using $15 \mathrm{~N}$ tracer additions. Limnology and Oceanography 58: 1271-1285.

Lewis, D., J. Schade, A. Huth, and N. Grimm. 2006. The spatial structure of variability in a semi-arid, fluvial ecosystem. Ecosystems 9:386-397.

Martí, E., N. B. Grimm, and S. G. Fisher. 1997. Pre- and post-flood retention efficiency of nitrogen in a Sonoran Desert stream. Journal of the North American Benthological Society 16:805819.

Mulholland, P. J. 2004. The importance of in-stream uptake for regulating stream concentrations and outputs of $\mathrm{N}$ and $\mathrm{P}$ from a forested watershed: evidence from long-term chemistry records for Walker Branch watershed. Biogeochemistry 70: 403-426.

Mulholland, P. J., A. M. Helton, G. C. Poole, R. O. Hall, S. K. Hamilton, B. J. Peterson, J. L. Tank, L. R. Ashkenas, L. W. Cooper, C. N. Dahm, W. K. Dodds, S. E. G. Findlay, S. V. 
Gregory, N. B. Grimm, S. L. Johnson, W. H. McDowell, J. L. Meyer, H. M. Valett, J. R. Webster, C. P. Arango, J. J. Beaulieu, M. J. Bernot, A. J. Burgin, C. L. Crenshaw, L. T. Johnson, B. R. Niederlehner, J. M. O'Brien, J. D. Potter, R. W. Sheibley, D. J. Sobota, and S. M. Thomas. 2008. Stream denitrification across biomes and its response to anthropogenic nitrate loading. Nature 452:202-205.

Mulholland, P., J. Tank, and J. Webster. 2002. Can uptake length in streams be determined by nutrient addition experiments? Results from an interbiome comparison study. Journal of the North American Benthological Society 21:544-560.

Mulholland, P. J., and J. R. Webster. 2010. Nutrient dynamics in streams and the role of J-NABS. Journal of the North American Benthological Society 29:100-117.

Murphy, J., and J. P. Riley. 1962. A modified single solution method for the determination of phosphate in natural waters. Analytica Chimica Acta 27:31-36.

Newbold, J. D., J. W. Elwood, R. V. O'Neill, and A. L. Sheldon. 1983. Phosphorus dynamics in a woodland stream ecosystem: a study of nutrient spiralling. Ecology 64:1249-1265.

Newbold, J. D., J. W. Elwood, R. V. O'Neill, and W. van Winkle. 1981. Measuring nutrient spiralling in streams. Canadian Journal of Fisheries and Aquatic Sciences 38:860-863.

Ninyerola, M., X. Pons, and J. M. Roure. 2000. A methodological approach of climatological modelling of air temperature and precipitation through GIS techniques. International Journal of Climatology 20:1823-1841.

Payn, R. A., M. N. Gooseff, B. L. McGlynn, K. E. Bencala, and S. M. Wondzell. 2009. Channel water balance and exchange with subsurface flow along a mountain headwater stream in Montana, United States. Water Resources Research 45:W11427.

Peterson, B. J., W. M. Wollheim, P. J. Mulholland, J. R. Webster, J. L. Meyer, J. L. Tank, E. Martí, W. B. Bowden, H. M. Valett, A. E. Hershey, W. H. McDowell, W. K. Dodds, S. K. Hamilton, S. Gregory, and D. D. Morrall. 2001. Control of nitrogen export from watersheds by headwater streams. Science 292:86-90.
Reardon, J., J. A. Foreman, and R. L. Searcy. 1966. New reactants for the colorimetric determination of ammonia. Clinica Chimica Acta 14:203-205.

Reddy, K., O. Diaz, L. Scinto, and M. Agami. 1995. Phosphorus dynamics in selected wetlands and streams of the lake Okeechobee Basin. Ecological Engineering 5:183-207.

Roberts, B. J., and P. J. Mulholland. 2007. In-stream biotic control on nutrient biogeochemistry in a forested stream, West Fork of Walker Branch. Journal of Geophysical Research 112. doi:10.1029/2007JG000422

Uehlinger, U. 2000. Resistance and resilience of ecosystem metabolism in a flood-prone river system. Freshwater Biology 45: 319-332.

Vitousek, P. M., and W. A. Reiners. 1975. Ecosystem succession and nutrient retention: a hypothesis. BioScience 25:376381.

von Schiller, D., V. Acuña, D. Graeber, E. Martí, M. Ribot, S. Sabater, X. Timoner, and K. Tockner. 2011a. Contraction, fragmentation and expansion dynamics determine nutrient availability in a Mediterranean forest stream. Aquatic Sciences 73: 485-497.

von Schiller, D., S. Bernal, and E. Martí. 2011b. Technical note: a comparison of two empirical approaches to estimate instream net nutrient uptake. Biogeosciences 8:875-882.

von Schiller, D., E. Martí, J. L. Riera, M. Ribot, A. Argerich, P. Fonolla, and F. Sabater. 2008. Inter-annual, annual, and seasonal variation of $\mathrm{P}$ and $\mathrm{N}$ retention in a perennial and an intermittent stream. Ecosystems 11:670-687.

Webster, J. R., and B. C. Patten. 1979. Effects of watershed perturbation on stream potassium and calcium dynamics. Ecological Monographs 49:51-72.

Webster, J. R., and H. Valett. 2006. Solute dynamics. Pages 169-185 in F. R. Hauer and G. A. Lamberti (editors). Methods in stream ecology. Academic Press, San Diego, California.

Zar, J. H. 2010. Biostatistical analysis. Prentice Hall, Upper Saddle River, New Jersey. 